\title{
Infectious diseases affecting occupational divers: review of 2017 literature
}

\author{
Richard Pougnet ${ }^{1,2}$, Laurence Pougnet ${ }^{1,2}$, Anne Henckes ${ }^{1,3}$, Ingrid Alliot ${ }^{4}$, \\ David Lucas $^{1}$, Jean-Dominique Dewitte ${ }^{1}$, Brice Loddé ${ }^{1,5}$ \\ ${ }^{1}$ French Society of Maritime Medicine (SFMM), France \\ ${ }^{2}$ Medical Laboratory, Military Hospital, Clermont-Tonnerre, Brest, France \\ ${ }^{3}$ Hyperbaric Medicine Unit, Teaching Hospital of Cavale Blanche, Brest, France \\ ${ }^{4}$ Environmental Laboratory of French Navy, Brest, France \\ ${ }^{5}$ EA 3149, Laboratoire d'Etudes et de Recherche en Sociologie (LABERS), Sociology, European University of Brittany, Brest, France
}

\begin{abstract}
Background: Occupational divers are prone to many health risks. For instance, they can get infections. We reviewed the infectious diseases in occupational divers.

Materials and methods: This is a literature review which went on up to 31.12.2017. The research was carried out on Medline and Scopus databases, in French and English languages.

Results: Fifteen papers report cases of infections in occupational divers. They are mainly skin infections, but also ear-nose-throat and ophthalmological infections.

Discussion and conclusions: According to data collected, infections among occupational divers are quite scarce. These diseases are not specific to the workplace, and are comparable with data on recreational diving. Prevention is mainly based on hygiene and equipment maintenance.
\end{abstract}

(Int Marit Health 2018; 69, 3: 176-180)

Key words: "Diving" [Mesh], "Infectious Disease Medicine" [Mesh], "Disease Outbreaks" [Mesh], "Occupational Medicine" [Mesh]

\section{INTRODUCTION}

The development of work techniques in hyperbaric environment has brought about specific diseases, such as decompression sickness, dysbaric osteonecrosis [1-6]. However, divers are also prone to many other risks, specific to water such as a risk of drowning and traumatisms $[7,8]$.

Moreover, diving in the sea may increase the risk of infections. A recent review showed for instance that halophile microorganisms may prove to be pathogen to humans [9]. The main infectious diseases which were diagnosed for recreational activities are otitis, conjunctivitis, breathing infections and diarrhoea syndromes [9]. As far as we know divers are subjects to the same risks as people on the surface. However, diving may have effects on the immunity system, especially because of the making of anti-oxidizers and oxygen reactive species; some authors described changes in activity of neutrophil polynuclear which could increase the risk of infections [10,11]. Several infections are described regarding recreational diving [12]. Yet, occupational divers seem to be running far fewer risks [13]. Furthermore in order to characterise biological hazards some teams studied the microbiologic environment surface parameters to finally assess the infectious risk on divers [14].

The subject of this article is then to point out the knowledge about infectious diseases on occupational divers with the description of infections and microorganisms.

\section{MATERIALS AND METHODS}

This is a review of medical literature. Observational retrospective studies and cross-sectional studies, systematic reviews, case reports and expert opinions published in English or French were identified from the Medline ${ }^{\circledR}$ and Scopus ${ }^{\circledR}$ databases until the $31^{\text {st }}$ December 2017. 
The following keywords were used in English on Medline ${ }^{\circledR}$ : (“Infectious Disease Medicine” [Mesh] OR “Infectious Disease Incubation Period” [Mesh] OR “Infectious Disease Transmission, Vertical” [Mesh] OR “Disease Transmission, Infectious" [Mesh] OR "Disease Reservoirs" [Mesh] OR "Disease Vectors" [Mesh] OR "Disease Outbreaks" [Mesh] OR "Zoonoses" [Mesh] OR "Contact Tracing" [Mesh] OR "Bone Diseases, Infectious" [Mesh]) AND “Diving” [Mesh]. There were only 8 articles. On Scopus ${ }^{\circledR}$, the researches were done with English keywords: div* AND inf*. In French, "TITLE-ABSKEY (plong*) AND (LIMIT-TO(SUBJAREA, “MEDI”)" were used. There were 287 articles. The literature research identified a total of 295 references that were included in the two medical databases. A doctor made a first selection from abstracts. Then selected articles, abstracts and full-text articles that met our eligibility criteria were included in this review.

Data were extracted from each article. Type of infections and type of microorganisms were summarised.

\section{RESULTS \\ GENERAL RESULTS}

Sixteen articles have been analysed. Some have displayed the presence of pathological microorganisms: in diving equipment [12], in sea water or in the life environment of offshore divers [15-17]. The most commonly described diseases were dermatological, ophthalmic and ear-nosethroat (ENT) diseases (Table 1).

\section{DERMATOLOGY}

Several kinds of infections have then been described: bacterial infections, fungoid infections [15-23]. Schane [20] followed-up saturation dives of 100 scientific missions of 7 to 14 days. The study was carried out for 11 years, involving 515 scientists. During their missions, the scientists dived 7 hours each day to carry out their research. Schane [20] described several skin infections.

Ahlén et al. [15, 16, 21] performed a longitudinal study for 14 years, with almost a thousand divers, in order to get clear indications of the genotypes of $P$. aeruginosa involved in the skin infections of the divers. The proliferation of the $P$. aeruginosa was strengthened by humidity, as well as by life in hyperbaric environment. Divers working several weeks in saturation for heavy work were therefore more affected by this infection. Promiscuity induced cross-contamination between members of the same working group. The genotyping showed the presence of more than 90 different genotypes [22]. Some genotypes were present in saturation occupation environment. In other cases, the infection source was a diver who had been colonised before the working session. Finally, some genotypes were also found in freshwater [15, 16]. Prevalence of some genotypes was greater in divers than in the general population $[15,16]$. Stereotype 011 was the most represented as for the infections in swimming pools $[15,16]$. The comparative study between samples of 191 infectious cases and 291 samples taken in the occupational environment of divers showed 8 common serotypes. In other words, divers were contaminated by their working environment. These serotypes survived several years in these environments making the disinfection difficult.

In 2003, Wang et al. [23] studied an epidemic of infections characterised by boils, folliculitis and small abscesses involving different body sites. The study of antibiogram showed that bacteria were the Methicillin-resistant Staphylococcus aureus (MRSA). Analysis of DNA restriction pattern by pulse field gel electrophoresis (PFGE) was done. PFGE showed it was the same MRSA for all divers. The origin of this epidemic was one of the divers. The man was colonised before.

\section{OPHTHALMOLOGY}

An outbreak of haemorrhagic conjunctivitis took place on a cruise ship in the Fiji Islands [24]. The epidemic affected 39 persons during a 6-day expedition. Recreational divers were concerned. The diagnosis was established by a physician and $46.7 \%$ of microbiological analyses were positive. The index case was the only occupational diver of the ship (the diving instructor). The transmission vector was the snorkels because of the lack of disinfection.

\section{EAR-NOSE-THROAT}

One of the main infections among occupational divers is the external otitis $[25,26]$. The main microorganism was the Pseudomonas aeruginosa [21]. In 1977, Alcock [13] studied the prevailing colonisations of external auditory canal of 58 divers. They showed that $67 \%$ of the divers studied were colonised by $P$. aeruginosa in the external auditory canal [13]. Several factors triggered this disease: dampness, pressure and promiscuity when divers remain in saturation for several weeks. Wang et al. [23] described nose infections and external otitis due to MRSA.

In an article about microbiology, Chen et al. [27] compared the genetic sequences of $P$. aeruginosa in occupational divers, using a multifocus sequence typing (MILST). Keeping in mind the high prevalence of multidrug resistance in the China sea, the researchers evaluated the virulence of the sources using the Caenorhabditis elegans fast killing assay. They identified 64 different genotypes of this $P$. aeruginosa: ST274 represented $18.5 \%$ of the isolated genotypes and ST260, 15.6\%. The virulence test from the C. elegans showed a stronger virulence from these genotypes than from the reference genotypes.

Reveli etal. [28] showed the prevalence of fungal otitis [26]. This study was led on 6 divers with a diving experience of 360 hours. They reported 4 cases of fungal otitis, especially when the diver had a history of barotrauma. 


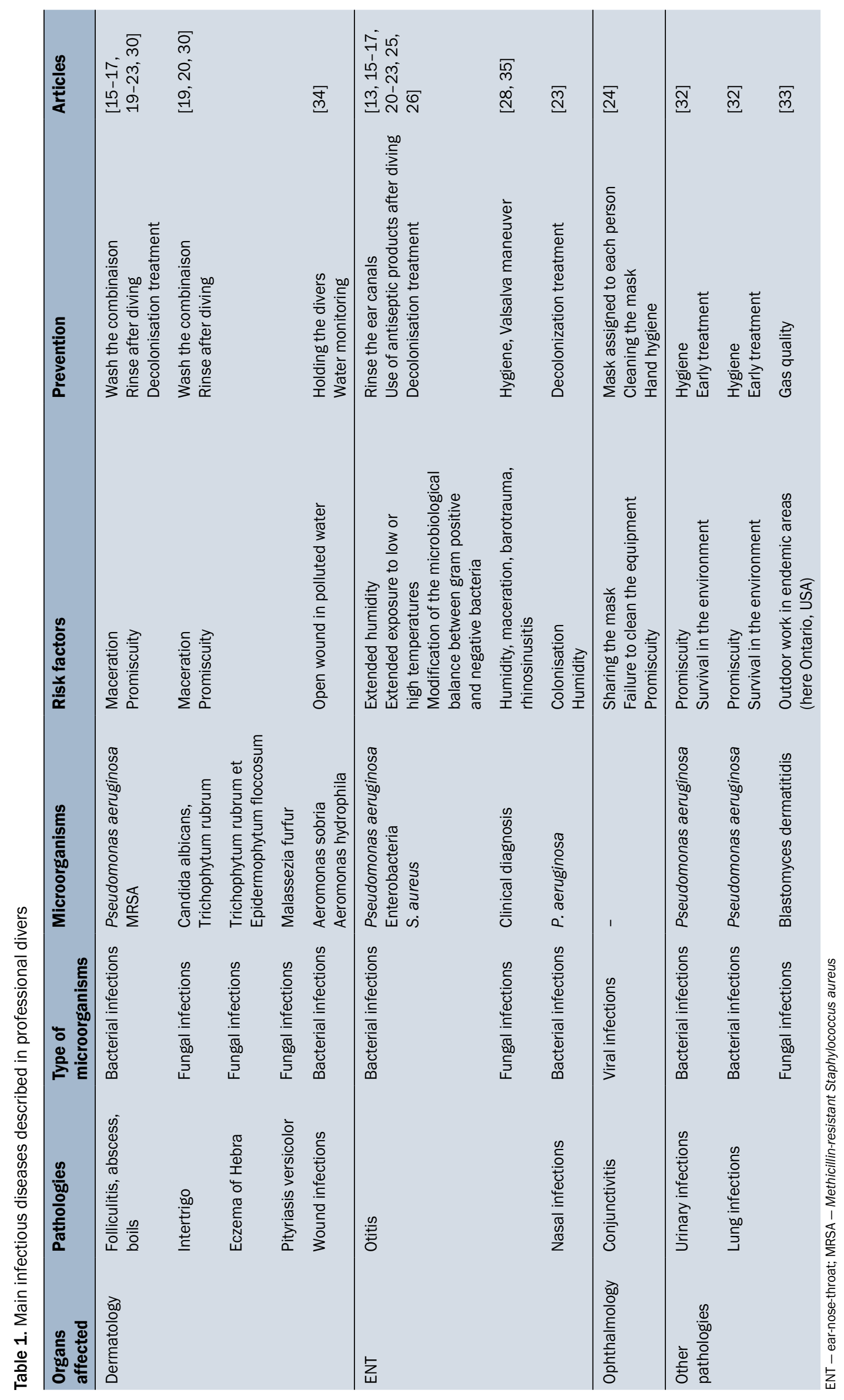




\section{OTHERS}

A 25-year-old man got stung from a sea-urchin during a dive in the Mediterranean Sea [29]. 48 hours on, the stung area had become swollen and was causing severe pain. The examination revealed that he presented an osteomyelitis caused by Pseudomonas aeruginosa.

Several lung infections have been described [12, 31]. For pulmonary diseases, Neubauer et al. [12] showed that the prevalence of serologies positive to Legionellae species was significantly increased in the diver's group vs. the general population.

A unique case of fungi pulmonary infection of blastomycosis was described. The patient was an occupational diver in the building industry. He was then exposed to different dusts on the wharves, on work places in Ontario [32]. The patient died of an acute respiratory failure.

\section{DISCUSSION}

This literature review showed infections regarding occupational divers. These diseases were mainly dermatological, ophthalmological or ENT infections.

Data about occupational diver's infections finally appear to be scarce. Several reasons might explain this and are linked to the limits of our research. Firstly, these diseases can occur both among recreational divers and occupational divers. However, recreational divers are numerous all around the world. So that the data concerning occupational divers can be regarded as insignificant. Infectious cases from occupational divers may be of lighter interest for publication. On the other hand, the occupational divers' medical follow-up may be different according to the country. Many cases may not have been screened in occupational health department [33]. Our review of the literature did not allow to estimate the prevalence of these pathologies, or to estimate the risk of infection. Only the prospective studies by country and type of activity might assess these prevalences. It would be interesting to make a prospective study to assess this health issue.

The prevalence of infections is very important among recreational divers. Thus, Strutz [34] showed that the main infection is external otitis. Other studies showed the same results [35]. Several triggering factors are described: including middle ear barotrauma, removal of lipid from the skin, prolonged exposure to high humidity and temperature [34-36].

On the contrary, some infections described among recreational divers are less likely to be seen among occupational divers. Honner et al. [37] notably described mastoiditis in a diver after contact with water contaminated by harmful alga bloom, commonly known as red tide. These infections generally develop in patients with factors of immunodepression. Occupational divers benefit from a medical follow-up. Some diseases are not compatible with the diving profession.
In France, for example, a type 1 diabetic person could not practise occupational diving.

However, the diver described by Honner et al. [37] had no such immunodepression. He had dived in particularly polluted water. The rate of coliform bacteria was very high. The occupational divers, as for them, are not allowed to dive in such waters, or, if it is the case, they dive in a waterproof suit [14]. This may explain a lower prevalence of infections in professional divers than among recreational divers. Indeed, few infections among recreational divers are caused by water pollution. A case of septic arthritis following a recreational dive was described on a hand having no cutaneous lesion [38].

Furthermore one case of otitis media was described on a Greek female recreational diver by Tsakris et al. [39]. The origin of the infection was the Vibrio sp. which proliferates in these waters. Several articles described zoonoses by helminthiasis among recreational divers, including in Europe with 6 cases, 4 of which in France and Italy [40].

The primary prevention consists in avoiding getting in contact with waters containing a great quantity of germs [14]. The second side of the primary prevention consists in applying of good hygiene measures: rinsing the equipment, shower after diving, steady cleaning of the equipment with antiseptic soaps; or also, the maintenance of the saturation systems [17]. The secondary prevention may also focus on infection screening and early treatment.

\section{CONCLUSIONS}

Infections among divers are well known. Yet there are few articles related to occupational diving. This review has brought to the fore that the main diseases are ophthalmological, ENT and dermatological infections. The main pathogen is $P$. aeruginosa. The prevention for occupational divers concerns several aspects of diving: water quality, quality of equipment, personal hygiene and cleaning of diving equipment.

There is probably an underestimation of the prevalence of these infections. Further screening should be done for a better identification of the issue and estimation of prevalence.

\section{REFERENCES}

1. Christophe Dupuy et Mathieu Coulange. Histoire de la plongée et techniques actuelles. In Brice Loddé (ed), Traité de Médecine Maritime. Paris, Lavoisier. 2015.

2. Mahon RT, Regis DP. Decompression and decompression sickness. Compr Physiol. 2014; 4(3): 1157-1175, doi: 10.1002/cphy. c130039, indexed in Pubmed: 24944033.

3. Héritier F, Avanzi P, Nicod L. Poumons et plongée. [Lungs et diving]. Rev Med Suisse. 2014; 10(451): 2182-6, 2188, indexed in Pubmed: 25603564.

4. Lance RM, Bass CR. Underwater blast injury: a review of standards. Diving Hyperb Med. 2015; 45(3): 190-199, indexed in Pubmed: 26415071. 
5. Uguen M, Pougnet R, Uguen A, et al. Dysbaric osteonecrosis among professional divers: a literature review. Undersea Hyperb Med. 2014; 41(6): 579-587, indexed in Pubmed: 25562949.

6. Uguen M, Pougnet R, Uguen A, et al. Dysbaric osteonecrosis in professional divers: two case reports. Undersea Hyperb Med. 2015; 42(4): 363-367, indexed in Pubmed: 26403020.

7. Byard RW. Commercial fishing industry deaths - forensic issues. J Forensic Leg Med. 2013; 20(3): 129-132, doi: 10.1016/j. jflm.2012.05.010, indexed in Pubmed: 23472787.

8. Clenney TL, Lassen LF. Recreational scuba diving injuries. Am Fam Physician. 1996; 53(5): 1761-1774, indexed in Pubmed: 8623700.

9. Pougnet R, Pougnet L, Allio I, et al. Maritime environment health risks related to pathogenic microorganisms in seawater. Int Marit Health. 2018; 69(1): 35-45, doi: 10.5603/IMH.2018.0006, indexed in Pubmed: 29611612.

10. Benestad HB, Hersleth IB, Hardersen $\mathrm{H}$, et al. Functional capacity of neutrophil granulocytes in deep-sea divers. Scand J Clin Lab Invest. 1990; 50(1): 9-18, indexed in Pubmed: 2315648.

11. Brubakk AO, Ross JAS, Thom SR. Saturation diving; physiology and pathophysiology. Compr Physiol. 2014; 4(3): 1229-1272, doi: 10.1002/cphy.c130048, indexed in Pubmed: 24944036.

12. Neubauer B, Tetzlaff K, Langfeldt N, et al. Occurrence of bacteria pathogenic to man in different types of diving apparatuses. Int Marit Health. 1999; 50(1-4): 29-37, indexed in Pubmed: 10970269.

13. Alcock SR. Acute otitis externa in divers working in the North Sea: a microbiological survey of seven saturation dives. J Hyg (Lond). 1977; 78(3): 395-409, indexed in Pubmed: 405421.

14. Pougnet R, Allio I, Pougnet L. Prevention of infectious diseases in harbour divers: how environmental parameters can help. Int Marit Health. 2015; 66(3): 186-187, doi: 10.5603/IMH.2015.0037, indexed in Pubmed: 26394322.

15. Ahlén C, Mandal LH, Iversen OJ. Identification of infectious Pseudomonas aeruginosa strains in an occupational saturation diving environment. Occup Environ Med. 1998; 55(7): 480-484, indexed in Pubmed: 9816382.

16. Ahlén C, Iversen OJ, Risberg J, et al. Diver's hand: a skin disorder common in occupational saturation diving. Occup Environ Med. 1998; 55(2): 141-143, indexed in Pubmed: 9614401.

17. Ahlen C, Mandal LH, Iversen OJ. An in-field demonstration of the true relationship between skin infections and their sources in occupational diving systems in the North Sea. Ann Occup Hyg. 2003; 47(3): 227-233, indexed in Pubmed: 12639836.

18. Bonin JP. Accidents dermatologiques et dermo-allergiques liés à la plongée et à la baignade. Le Concours Médical. 1998; 110(4): 241-250.

19. Le Ma. Peau et plongée sous-marine. Nouv Dermatol. 1999; 18: 262-263.

20. Schane W. Prevention of skin problems in saturation diving. Undersea Biomed Res. 1991; 18(3): 205-207, indexed in Pubmed: 1853473.

21. Ahlén C, Mandal LH, Iversen OJ. The impact of environmental Pseudomonas aeruginosa genotypes on skin infections in occupational saturation diving systems. Scand J Infect Dis. 2001; 33(6): 413-419, indexed in Pubmed: 11450859.

22. Ahlén C, Mandal LH, Johannessen LN, et al. Survival of infectious Pseudomonas aeruginosa genotypes in occupational saturation diving environment and the significance of these genotypes for recurrent skin infections. Am J Ind Med. 2000; 37(5): 493-500, indexed in Pubmed: 10723043.

23. Wang J, Barth S, Richardson M, et al. An outbreak of Methicillin-resistant Staphylococcus aureus cutaneous infection in a saturation diving facility. Undersea Hyperb Med. 2003; 30(4): 277-284, indexed in Pubmed: 14756230.

24. Olsson DJ, Grant WD, Glick JM. Conjunctivitis outbreak among divers. Undersea Hyperb Med. 2008; 35(3): 169-174, indexed in Pubmed: 18619112.

25. Cobet AB, Dimmick RL. Tektite-I program: aerobiological aspects. Aerosp Med. 1970; 41(6): 617-620, indexed in Pubmed: 4392834.

26. Levine HB, Cobet AB. The tektite-I dive. Mycological aspects. Arch Environ Health. 1970; 20(4): 500-505, indexed in Pubmed: 4393404.

27. Chen SH, Chen RY, Xu XL, et al. Multilocus sequencing typing of Pseudomonas aeruginosa isolates and analysis of potential pathogenicity of typical genotype strains from occupational oxyhelium saturation divers. Undersea Hyperb Med. 2014; 41(2): 135-141, indexed in Pubmed: 24851551.

28. Revelli L, D'Alatri L, Scorpecci A, et al. ENT function in a 14-days guinness scuba dive. Int J Sports Med. 2012; 33(1): 31-35, doi: 10.1055/s-0031-1283187, indexed in Pubmed: 22095323.

29. García J, Monfort J, Blanch J, et al. [Osteomyelitis by Pseudomonas aeruginosa in a submariner]. Med Clin (Barc). 2005; 124(20): 795-796, indexed in Pubmed: 15927108.

30. Robinet C, Guillou L, Galland FM, et al. Médecine et armées Peau et plongée. 1997; 25(8): 679-686.

31. Chim H, Soo KH, Low E, et al. Severe acute respiratory syndrome in a naval diver. Military Medicine. 2006; 171(6): 491-493, doi: 10.7205/milmed.171.6.491.

32. Kroll RR, Grossman RF. Pulmonary blastomycosis in a professional diver: an occupational risk. Can Respir J. 2013; 20(5): 340-342, doi: 10.1155/2013/646854, indexed in Pubmed: 23717820.

33. Pougnet $R$, Uguen $M$, Verdier $G$, et al. Predicted nine-year risk of diabetes among professional divers: a prospective study. Int Marit Health. 2015; 66(2): 87-92, doi: 10.5603/IMH.2015.0021, indexed in Pubmed: 26119678.

34. Strutz J. [Otorhinolaryngologic disorders associated with diving]. HNO. 2008; 56(5): 499-504, 506, doi: 10.1007/s00106-0081742-x, indexed in Pubmed: 18415066.

35. Azizi MH. Ear disorders in scuba divers. Int J Occup Environ Med. 2011; 2(1): 20-26, indexed in Pubmed: 23022815.

36. Skogstad M, Eriksen T, Skare O. A twelve-year longitudinal study of hearing thresholds among professional divers. Undersea Hyperb Med. 2009; 36(1): 25-31, indexed in Pubmed: 19341125.

37. Honner S, Kudela RM, Handler E. Bilateral mastoiditis from red tide exposure. J Emerg Med. 2012; 43(4): 663-366.

38. Berianu F, Ginsburg W, Trigg S, et al. Destructive arthritis of the hand after diving. J Rheumatol. 2014; 41(12): 2486, doi: 10.3899/ jrheum.140567, indexed in Pubmed: 25452182.

39. Tsakris A, Psifidis A, Douboyas J. Complicated suppurative otitis media in a Greek diver due to a marine halophilic Vibrio sp. J Laryngol Otol. 1995; 109(11): 1082-1084, indexed in Pubmed: 8551126.

40. Bracaglia G, Ranno S, Mancinelli L, et al. A waterborn zoonotic helminthiase in an Italian diver: a case report of a cutaneous Sparganum infection and a review of European cases. Pathog Glob Health. 2015; 109(8): 383-386, doi: 10.1080/20477724.2015. 1123901, indexed in Pubmed: 26751512. 